\title{
Surrogate Role of CD85k on Monocytic Lineage Involved Leukemogenesis Biology and Clinical Aspect
}

\author{
Hasnaa A. Abo-Elwafa ${ }^{1 *}$, Shereen P. Aziz' ${ }^{1}$, Heba A. Ahmed ${ }^{1}$, Elsayed Mostafa Ali², Doaa S. Elsaied ${ }^{1}$ \\ ${ }^{1}$ Clinical Pathology Department, Sohag Faculty of Medicine, Sohag University, Sohag, Egypt \\ ${ }^{2}$ Clinical Oncology Department, Sohag Faculty of Medicine, Sohag University, Sohag, Egypt \\ Email: *Hasnaa_aboalwafa@med.sohag.edu.eg
}

How to cite this paper: Abo-Elwafa, H.A., Aziz, S.P., Ahmed, H.A., Ali, E.M. and Elsaied, D.S. (2018) Surrogate Role of CD85k on Monocytic Lineage Involved Leukemogenesis Biology and Clinical Aspect. Open Journal of Blood Diseases, 8, 61-73. https://doi.org/10.4236/ojbd.2018.84007

Received: April 7, 2017

Accepted: October 9, 2018

Published: October 12, 2018

Copyright (c) 2018 by authors and Scientific Research Publishing Inc. This work is licensed under the Creative Commons Attribution International License (CC BY 4.0).

http://creativecommons.org/licenses/by/4.0/

\begin{abstract}
Background: Unique receptor involved in leukemogenesis is CD85k; an immuneglobulin receptor for immune tolerance, CD36 is glycoprotein mediates cellular adhesion and metastatic spread, CD14, CD15 considered common monocytic markers. Aims: to investigate CD85k with monocytic lineage involved leukemia (MLIL) markers in leukemia pathogenesis and clinical presentation. Patients and Methods: 47 patients (32 diagnosed acute myeloid leukemia (AML); 15 non-malignant hematological disease as a control), were included, aged from 2 to 80 years, all subjected to peripheral blood (P.Bl) and bone marrow (B.M) examination, immunophenotyping (IPT) using FASC Canto four color flow cytometer (FCM) Becton Dickenson (BD) USA, for CD13, CD33, MPO, HLA-DR, CD34, CD38, CD117, CD14, CD15 and CD36 the Mo Abs supplied by B.D Bioscience, and anti CD85k Mo Abs by Aveda de Coimbra Flamenco, reference No. 1399990130. Results: Frequency of CD85k is 19/32 (59.37\%) of AML; 14/14 (M4/M5) 100\% positive CD85k, insignificant correlations of CD85k to sex, lymphadenopathy or organomegaly, platelets count and P.Bl blast $(\mathrm{P}>0.05)$, significant to age $<35$ years, WBCs $>50,000 \times$ $10^{9} / \mathrm{l}, \mathrm{Hb}<7 \mathrm{~g} / \mathrm{dl}, \mathrm{BM}$ blasts, CD34 and HLA-DR CD33, CD13, CD38 (P < 0.05), insignificant correlations to CD36, CD14, CD15 and CD117 ( $P>0.05)$. Conclusion: Although CD85k is MLIL associated marker, it is not correlated with other MLIL markers with frequency $100 \%$ in MLIL and 59.37\% in AML, age predisposition is $<35$ years with no sex variation, significant correlation to progenitor and myeloid markers, it's a crucial role in leukemogenesis biology, not in clinical presentations, considered good follow up predictor MLIL marker.
\end{abstract}

\section{Keywords}

CD85k, Monocytic Lineage Leukemia 


\section{Introduction}

The unique synergistic action of membrane bound proteins in leukemogenesis in monocytic lineage involved (MLIL) leukemia include immune escape by immunoglobulin inhibitory receptor CD85k and cellular adhesion and metastatic spread by glycoprotein CD36 [1] [2]. CD36 mediating adhesion process to endothelial cells and in promoting tumor spreading and organ infiltrations [3]. Monocytoid dendritic cells with high ILT3 levels suppress T cell activation and are tolerogenic, ILT3 levels are higher in patients being treated with type I IFN, supporting the concept that IFN-induced ILT3 expression is immunosuppressive [1] [2] [4]. The cytoplasmic tail of ILT3 contains immune tyrosine-based inhibition receptor recruits and activates tyrosine phosphatases. Ligation of CD85k on dendritic cells blocks the activation and downstream signaling [5] [6] [7]. CD85k expressed by, monocytes, dendritic cells and endothelial cells. It is encoded in chromosome 19 [8]. CD85k has a crucial role in tolerogenic activity of antigen presenting cells and tumor escape [9]. Also it promotes conversion alloreactive $\mathrm{CD} 4$ to regulatory $\mathrm{T}$ cell (Terg). It inhibits $\mathrm{T}$ cell proliferation and induces CD8 differentiation. Crosslinking of CD85k to monocyte receptor decrease activation [10]. In AML CD85k is sensitive marker with CD36 for monocytic differentiation [3] [11]. In MLIL CD85k co-expressed with CD34 and CD117 progenitor cells so it has a role in leukemogenesis [10]. AML with monocytic differentiation has a high risk of extra medullary disease, high leukocytic count and coagulation defect also genetic and cytogenetic abnormality [8]. The early clinical findings of AML are often vague and nonspecific [12]. Splenic enlargement and generalized lymphadenopathy are rare in AML [13]. Some patients may experience swelling of the gums because of infiltration of leukemic cells [14]. AML has several subtypes; treatment and prognosis differ between them, several markers can predict which drug may work best [15].

CD85k mainly has prognostic value in leukemia so it should be incorporated into the initial diagnosis work-up and leukemia monitoring [9]. CD85k is an important target for anticancer therapy [10]. Lack of CD85k expression leads to leukemia remission increase survival rate in animal model, also block leukemia development in transplantation [16].

\section{Subjects and Methods}

\subsection{Ethical Approval}

The present study was revised by the Scientific Ethical Committee of Sohag University Hospital; a written informed consent was taken from all patients groups. It was in accordance with the ethical standards of the institutional and/or national research committee and with the 1964 Helsinki declaration.

\subsection{Patients Selection}

32 newly diagnosed AML patients were rolled in the study, they attended to Sohag University Hospital, Hematology Unit of Clinical Pathology Department, 
from October 2014 to October 2016, they were aged from 2 to 80 years old with mean age $(31.77 \pm 19.49), 19$ males and 13 females and 15 subjects of non-malignant hematological disease (ITP), 8 males, 7 females; their ages ranged from 3 to 60 years with mean of $(15.47 \pm 15.46)$ of the same ethnic group as a control.

\subsection{Inclusion Criteria}

Newly diagnosed AML especially MLIL. All were subjected to:

Through history and clinical examination with stress on the presence and extent of leukemia involvement of liver, spleen, lymphadenopathy and gum hypertrophy.

\subsection{Laboratory Investigations}

\subsubsection{Sampling}

$3 \mathrm{ml}$ of venous blood were collected from each one, dispensed into (K-EDTA) B.D tube used for P.Bl hemogram. BM examinations (aspirate/biopsy) were done for all groups, diagnosis of AML based on morphological features of P.Bl and B.M smears, cytochemical tests and IPT data. Blood count using CellDyne-Ruby, automated cell counter, ABBOTT diagnostic (USA), with microscopic examination of stained P.Bl. and BMA smears for differential leucocytes count, blast cells percentage, morphological features and cytochemical stains.

\subsubsection{IPT of Blast Cells}

FCM FASC Canto four colors B.D; USA was used and the MoAbs supplied by B.D Bioscience, USA. The panel of fluorescein isothiocyanate (FITC), phycoerythrin (PE) and Peridinin chlorophyll (PerCP) conjugated MoAbs were used for each sample. Common progenitor marker, CD34, HLA-DR, CD38, CD117 Myeloid markers CD13, CD33, MPO, monocytic marker CD14, CD15, CD36, CD65, CD68. Lymphoid markers: B cell markers CD19, CD22, CD10, T cell markers CD2, CD3, CD5, CD7, FITC labeled MoAbs for detection of CD36 (B.D Bioscience, Cat. No.656151 USA). PE labeled Mo Abs for CD85k provided by Aveda de Coimbra Flamenco, Reference No. 1399990130.

\subsection{Procedure of Surface Membrane Markers}

Expression on blast cells:

\section{Reagents}

Sheath fluid, Phosphate buffered saline (PBS) ( $8.0 \mathrm{~g} / \mathrm{L} \mathrm{NaCl}, 0.2 \mathrm{~g} / \mathrm{L} \mathrm{k} \mathrm{Cl}, 1.15$ $\mathrm{g} / \mathrm{L} \mathrm{NaH}_{2} \mathrm{PO}_{4}$ and $\left.0.2 \mathrm{~g} \mathrm{kH}_{2} \mathrm{PO}_{4}\right)$ added to $100 \mathrm{~mL}$ of distilled water with $\mathrm{pH}$ adjusted at $7.3 \pm 0.2$. Lysing solution $\left(1.5 \mathrm{mmol} / \mathrm{L} \mathrm{NH}_{4} \mathrm{Cl}, 100 \mathrm{mmol} / \mathrm{L} \mathrm{KHCO}_{3}\right.$ and $10 \mathrm{mmol} / \mathrm{L}$ tetra $\mathrm{Na}$-EDTA) made up to 1 liter with distilled water, $\mathrm{pH}$ adjusted at 7.2. Negative isotypic control (appropriately labeled according to the MoAbs used) for determining the non-specific binding of MoAbs. MoAbs supplied by BD Bioscience, United States. 


\subsection{Procedure}

Blood was diluted with (PBS) so that WBCs count was adjusted between 5 and $10 \times 10^{9} / 1$. For each sample, sets of tubes were labeled for all the MoAbs to be used, including 1 tube for the appropriate negative isotypic control.

$50 \mu \mathrm{L}$ of diluted samples were delivered in each tube. $5 \mu \mathrm{L}$ of each MoAbs as well as of the isotypic negative control. The tubes were vortexed and incubated in the dark at room temperature for 15 minutes. The tubes were centrifuged at $500 \mathrm{rpm}$ for 5 minutes and the supernatant was discarded. Lysing solution (1.5 $\mathrm{mL}$ ) was added to each tube. The tubes were vortexed and incubated for $5-10$ minutes in the dark at room temperature. $2 \mathrm{ml}$ PBS was added and the tubes were vortexed. The tubes were centrifuged at $500 \mathrm{rpm}$ for 5 minutes and the supernatant was discarded. Cells were suspended in $500 \mu \mathrm{L}$ PBS to be ready for acquiring data by the FCM.

The expression of blast cells for CD85k was determined as a percentage from the gated blast cells population. Cells were considered positive for a certain marker when $\geq 20 \%$ of cells expressed it, except for CD34, cytoplasmic MPO and CD85K where its expression by $10 \%$ of cells was sufficient to confer positivity.

\subsection{Statistical Analysis}

The collected data were tabulated and analyzed using statistical package of social science (SPSS) version 17 software. Suitable statistical techniques were computed ANOVA test, Student's t test, Mann Whitney test and Kruskal Wallis for non-parametric values, correlation coefficient were used as tests of significance. Qualitative data were described in the form of number and percentage. Quantitative data were described in the form of mean \pm standard deviation (SD), range and median.

\subsection{Results}

The present study was carried on 47 patients thirty two diagnosed as AML including fourteen MLIL (M4/M5 cases), their age ranged from 2 to 80 years, with median age 29 years old (mean is $31.77 \pm 19.49$ ), they were nineteen males/thirteen females, and fifteen cases of non-malignant hematological disease (ITP); their age ranged from 3 to 60 with median age 15 years old (mean $15.47 \pm$ 15.46); seven males/eight females as a control.

Table 1 represents demographic data and clinical features in relation to CD85k expression, the positive rate of CD85k was 59.37\% in AML and $100 \%$ in MLIL patients. In this study we notice that; the age predisposition of CD85k expression in AML patients was that; (12/19 cases) were below 35 years old and (7/19 cases) were above 35 years old (significant $\mathrm{p}$ value $\mathrm{p}<0.05)$. About the sex variation, the number of AML males positive for CD85k was 10/19, while the positive females were $9 / 19$ with insignificant difference $(p>0.5)$. Hepatomegaly was observed in 18/32 patients AML (56.25\%) from which 12 patients were positive for CD85k (60\%); the other fourteen patient with normal liver size showed 
Table 1. Demographic data with clinical features and hematological variables in the studied patients.

\begin{tabular}{|c|c|c|c|c|c|}
\hline $\begin{array}{l}\text { Patients } \\
\text { Variables }\end{array}$ & AML group & $\mathrm{CD} 85 \mathrm{k}+\mathrm{Ve}$ & $\begin{array}{l}\text { AML subgroup } \\
\text { (MLIL) }\end{array}$ & Control & p-value \\
\hline Patients No & 32 & & 14 & 15 & NS \\
\hline \multicolumn{6}{|l|}{ Age (years) } \\
\hline Median (range) & $19(2-80)$ & & $20(2-74)$ & $15(3-60)$ & NS 0.06 \\
\hline$<35$ & $14(12)$ & & 10 & & S 0.03 \\
\hline$>35$ & $18(7)$ & & 4 & & NS 0.08 \\
\hline \multicolumn{6}{|l|}{ Sex } \\
\hline $\mathrm{M} / \mathrm{F}$ & $19 / 13$ & $(10 / 9)$ & $6 / 8$ & $8 / 7$ & NS 0.5 \\
\hline Hepatomegaly & $18(12)$ & & 12 & Normal & NS 0.3 \\
\hline Normal size & $14(7)$ & & 2 & & \\
\hline Splenomegaly & $20(15)$ & & 12 & Normal & NS 0.4 \\
\hline Normal size & $12(4)$ & & 2 & & \\
\hline Lymphadenopathy & $14(10)$ & & 10 & Normal & NS 0.2 \\
\hline No lymphadenopathy & $18(9)$ & & 2 & & \\
\hline WBCs $\times 10^{9} / 1$ & & & & $3.2-12.8$ & \\
\hline Range & $1.7-245$ & & $23-245$ & & \\
\hline$<50$ & 21 & & 9 & & \\
\hline$>50$ & 11 & & 5 & & S 0.02 \\
\hline \multicolumn{6}{|l|}{$\mathrm{Hb} \mathrm{g} / \mathrm{dl}$} \\
\hline Range & $3.7-12.6$ & & $4.5-8$ & $11-13.5$ & \\
\hline$<7$ & 19 & & 10 & & S 0.023 \\
\hline$>7$ & 13 & & 4 & & \\
\hline \multicolumn{6}{|l|}{ Platelets $\times 10^{9} / 1$} \\
\hline Range & $12-456$ & & $14-38$ & $243-427$ & \\
\hline$<100$ & 24 & & 14 & & S 0.02 \\
\hline$>100$ & 8 & & 0 & & \\
\hline \multicolumn{6}{|l|}{ P.Bl. blasts \% } \\
\hline Range & $11-91$ & & $14-69$ & 0.0 & NS 0.06 \\
\hline \multicolumn{6}{|l|}{ B.M blasts \% } \\
\hline Range & $24-93$ & & $23-78$ & 0.0 & NS 0.5 \\
\hline $\mathrm{CD} 85 \mathrm{k}+\mathrm{Ve}$ & & & & & HS 0.001 \\
\hline$\%$ Range & $(0.63-87.6)$ & (19) & $(23-87.6)$ & 0.0 & \\
\hline Mean \pm SD & $26.92 \pm 25.29$ & & 14 & & \\
\hline
\end{tabular}

AML: acute myeloid leukemia, MLIL: monocytic lineage involved leukemia, M: male, F: female, P.Bl: peripheral blood, BM: bone marrow, WBCs: white blood cells, Hb: hemoglobin, CD cluster of differentiation, HLA: human leukocytic Ag. 
$50 \%$ positive expression of CD85k (7 cases). Splenomegaly was observed in 20/32 ML patients $62.5 \%$, from which 15 patients were positive for CD85k (75\%) and five were negative; and the other twelve patients with normal size spleen showed 30\% positive for CD85k (4 cases). Lymphadenopathy was observed in 14/32 AML patients (43.75\%); nine patients from them showed positive CD85k 9/14 (64.28\%), and 10/18 patients without lymphadenopathy showed positive CD85k (55.55\%). All these data were insignificant to CD85k expression ( $p>0.05)$.

The positive rate expression of both CD $85 \mathrm{k}$ and other MLIL markers were zero within the control group. As regard the hematological variables, also in table-1; significant correlations of CD85k was found when WBCs count was more than $50 \times 10^{9} / \mathrm{l}(\mathrm{p}<0.05)$, Hb value was less than $7 \mathrm{~g} / \mathrm{dl}(\mathrm{p}<0.05)$, also significant correlation to the percentage of BM blasts. While platelet counts, the P.Bl blasts showed insignificant correlations ( $p>0.05$ ). We found that; the number of AML cases positive for progenitor markers were seventeen patients were positive for $\mathrm{CD} 34$, thirty were positive for $\mathrm{CD} 38,6$ cases were positive for $\mathrm{CD} 117$ and twenty four patients were positive for HLA-DR. While the number of positive cases for the rest MLIL markers were 6 patients were positive for CD14, 8 patients were positive for CD15 and only 3 cases were positive forCD36. Myeloid markers positivity showed that; CD13 was positive in twenty eight cases and CD33 was positive in thirty patients.

Table 2 represents the correlation of CD85k to the progenitors, myeloid and MLIL FCM markers. We notice that, there was insignificant correlation between CD85K and CD16, CD117, CD36, 235a.There was no correlation between CD85K and CD45, CD14 and CD15. There was positive significant correlation between CD85K and HLA-DR, CD34 and CD38, also CD13 and CD33 showed significant correlation. Details of FCM analysis were illustrated in Figure 1, Figure 2.

Comparison between MLIL and other types of AML as regards IPT were presented in Table 3, we found that the mean expression of CD45, CD13, CD33 was increased in MLIL than other AML group, with significant increase in CD45 ( $\mathrm{p}$ $=0.002$ ). On the other hand, the mean expression of MPO, CD38, CD117, CD34 was increased in other AML group than MLIL with significant $p$ value in CD 34, CD38, CD117 (P0.01, 0.005, 0.011 respectively). While the mean expression of HLA-DR, CD14, CD15 showed significant increase in MLIL group than other AML group $(\mathrm{p}<0.001)$ for all markers. The mean expression of CD36 and CD61 were higher in other AML group than MLIL group ( $\boldsymbol{P} 0.027$ and 0.01 respectively). High significant increase in the mean expression of 235a in other AML group than MLIL group $(\mathrm{p}<0.001)$. Finally the mean expression of CD85k is highly significant increase in MLIL group than other AML group (43.23 \pm 18.46 to $14.23 \pm 22.07) ; \mathrm{p}<0.001$.

\section{Discussion}

Membrane bound protein receptors play a crucial role in leukemogenesis, as 
Table 2. Spearmans' correlation of CD85k to clinical and hematological variables in AML patients.

\begin{tabular}{|c|c|c|}
\hline FCM markers & Spearman's correlation & $\mathrm{p}$ value \\
\hline Age & 0.33 & 0.06 (NS) \\
\hline \multirow[t]{2}{*}{ Sex } & 0.137 & 0.09 (NS) \\
\hline & WBCs & \\
\hline$<50 \times 10^{9} / 1$ & 0.111 & 0.148 (NS) \\
\hline$>50 \times 10^{9} / 1$ & 0.35 & $0.048(S)$ \\
\hline $\mathrm{Hb}<7 \mathrm{~g} / \mathrm{dl}$ & 0.346 & $0.034(\mathrm{~S})$ \\
\hline $\mathrm{Hb}>7 \mathrm{~g} / \mathrm{dl}$ & 0.23 & $0.22(\mathrm{NS})$ \\
\hline Platelets & 0.06 & 0.73 (NS) \\
\hline P.Bl blasts & 0.32 & 0.07 (NS) \\
\hline \multirow[t]{2}{*}{ B.M blasts } & 0.42 & $0.02(\mathrm{~S})$ \\
\hline & Progenitors & \\
\hline CD34 & 0.494 & $0.03(\mathrm{~S})$ \\
\hline HLA-DR & 0.544 & $0.004(S)$ \\
\hline CD38 & 0.471 & $0.035(\mathrm{~S})$ \\
\hline \multirow[t]{2}{*}{ CD117 } & 0.0435 & 0.734 (NS) \\
\hline & Myeloid & \\
\hline $\mathrm{CD} 13$ & 0.399 & $0.011(S)$ \\
\hline \multirow[t]{2}{*}{ CD33 } & 0.457 & $0.003(\mathrm{~S})$ \\
\hline & Monocytic & \\
\hline $\mathrm{CD} 14$ & 0.267 & $0.26(\mathrm{NS})$ \\
\hline $\mathrm{CD} 15$ & -0.363 & $0.12(\mathrm{NS})$ \\
\hline CD36 & 0.064 & 0.651 (NS) \\
\hline
\end{tabular}

they control cellular transduction, any up or down regulation alters the antigen recognition and promotes leukemic cells spread that is happen by CD85k which is immunoglobulin inhibitory receptor responsible for immune escape. CD36 is the glycoprotein responsible for cellular adhesion and infiltration processes, its overexpression leads to tumor metastasis and organ affection [1] [3] [4] [15] [17]. Formally cytochemical stains can confirm the leukemic cell type, the nonspecific esterase was used to identify monocytic component of poorly differentiated monoblastic leukemia [18]. Now with the advance in myeloid and monocytic lineage specific panels, and the IPT become the first and accurate laboratory test [19]. Also characterizations the biological function of each marker facilitate the associated correlation between different cell markers and clinical data [20]. The current study was carried out on thirty two newly diagnosed AML patients according to morphological, cytochemical and IPT criteria. The frequency of CD85k in was $59.37 \%$ in AML and $100 \%$ in MLIL, CD85k, which has more 

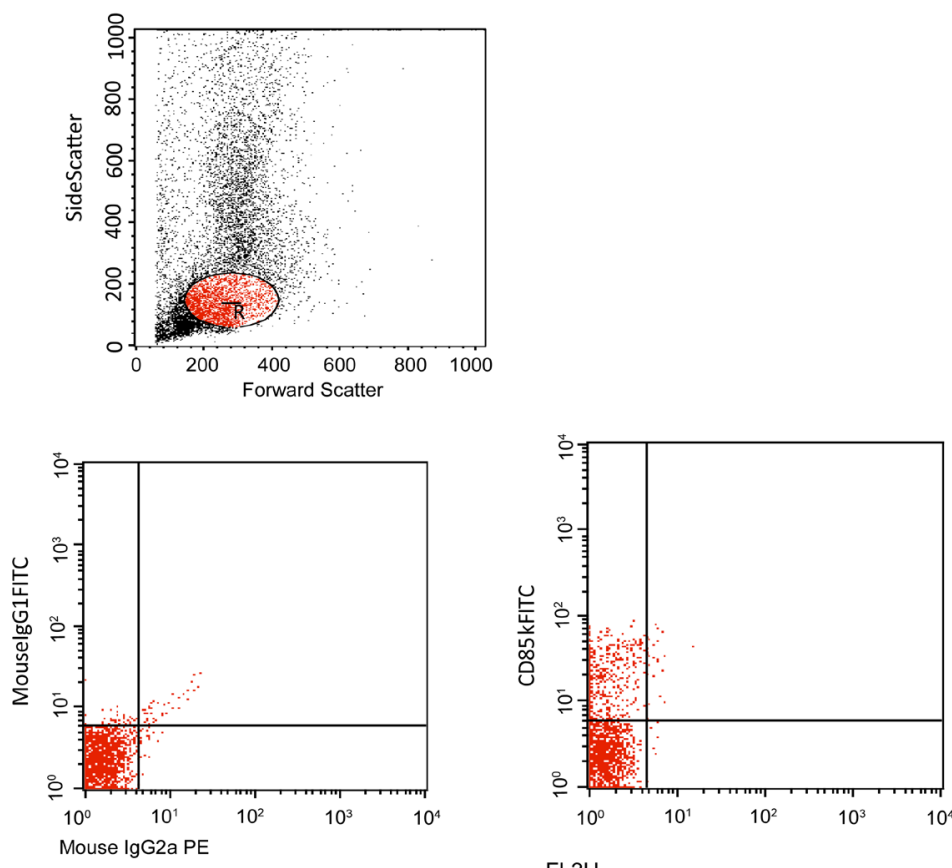

Acquisition Date: 06-Apr-16 Gate: G1 Gated Events: 2402 Total Events: 10000 X Parameter: FL2-H (Log) Y Parameter: CD85k FITC (Log)

Quad Events \% Gated \% Total X Mean X Geo Mean Y Mean Y Geo Mean

\begin{tabular}{cccccccc}
\hline UL & 551 & 22.94 & 5.51 & 1.54 & 1.39 & 22.37 & 18.32 \\
UR & 21 & 0.87 & 0.21 & 6.03 & 5.79 & 34.58 & 28.35 \\
LL & 1825 & 75.98 & 18.25 & 1.42 & 1.33 & 2.43 & 2.13 \\
LR & 5 & 0.21 & 0.05 & 5.54 & 5.52 & 3.86 & 3.68
\end{tabular}

Figure 1. FCM analysis of CD85k in AML M4 patient.
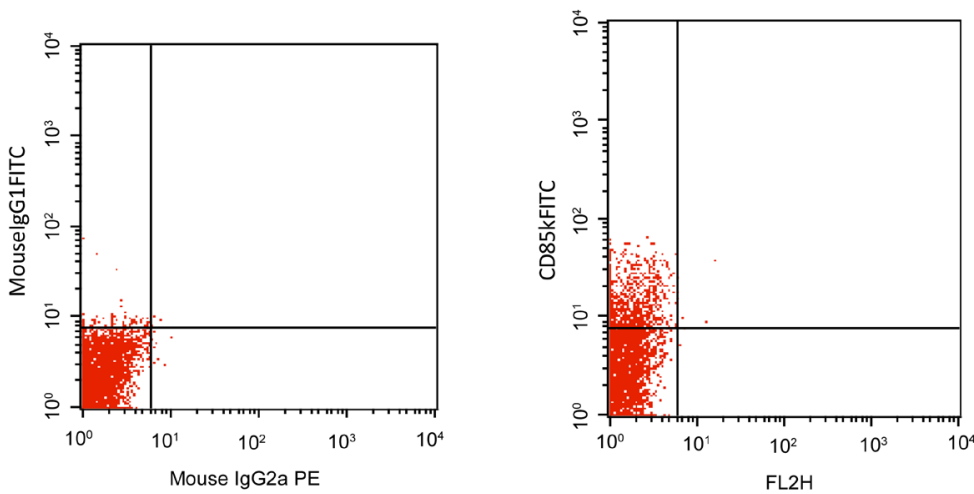

Quadrant Statistics

File: Data.002

Sample ID:

Log Data Units: Linear Values

Tube:Untitled

PatientID

Acquisition Date: 06-Apr-16

Panel:Untitled Acquisition Tube List

Gated Events:6004

X Parameter:FL2-H(Log)

Total Events: 10000

Y Parameter: CD85kFITC(Log) Quad Location: 6,8

Quad Events \% Gated \% Total X Mean X Geo Mean Y Mean Y Geo Mean

$\begin{array}{lccccccc}\text { UL } & 1164 & 19.39 & 11.64 & 1.71 & 1.52 & 15.21 & 13.44 \\ \text { UR } & 6 & 0.10 & 0.06 & 8.84 & 8.13 & 19.13 & 16.85 \\ \text { LL } & 4832 & 80.48 & 48.32 & 1.35 & 1.27 & 3.03 & 2.51 \\ \text { LR } & 2 & 0.03 & 0.02 & 6.71 & 6.70 & 6.24 & 6.13\end{array}$

Figure 2. FCM analysis of CD85k in AML M2 patient. 
Table 3. Comparison betweenMLIL and other types of AML as regards IPT.

\begin{tabular}{|c|c|c|c|}
\hline $\begin{array}{c}\text { FCM Markers } \\
\text { Expression \% }\end{array}$ & $\begin{array}{c}\text { MLIL } \\
(\text { No. }=14)\end{array}$ & $\begin{array}{l}\text { Other AML } \\
(\text { No. }=18)\end{array}$ & $P$ value \\
\hline \multicolumn{4}{|l|}{$\mathrm{CD} 45$} \\
\hline Mean \pm SD & $74.70 \pm 17.63$ & $89.744 \pm 7.0932$ & $0.002(\mathrm{~S})$ \\
\hline \multicolumn{4}{|l|}{ CD33 } \\
\hline Mean \pm SD & $79.9 \pm 12.93$ & $63.40 \pm 30.57$ & 0.06 (NS) \\
\hline \multicolumn{4}{|l|}{$\mathrm{CD} 13$} \\
\hline Mean \pm SD & $58.31 \pm 21.41$ & $52.69 \pm 28.0343$ & 0.539 (NS) \\
\hline \multicolumn{4}{|l|}{ MPO } \\
\hline Mean \pm SD & $2.302 \pm 2.27$ & $6.737 \pm 21.56$ & 0.451 (NS) \\
\hline \multicolumn{4}{|l|}{ CD38 } \\
\hline Mean \pm SD & $36.88 \pm 36.34$ & $67.32 \pm 26.79$ & $0.01(\mathrm{~S})$ \\
\hline \multicolumn{4}{|l|}{ CD34 } \\
\hline Mean \pm SD & $0.760 \pm 0.460$ & $26.15 \pm 31.58$ & $0.005(\mathrm{~S})$ \\
\hline \multicolumn{4}{|l|}{ CD 117} \\
\hline Mean \pm SD & $1.98 \pm 1.843$ & $25.24 \pm 31.951$ & $0.011(\mathrm{~S})$ \\
\hline HLADR & $69.321 \pm 23.642$ & $37.989 \pm 31.379$ & $<0.001$ (HS) \\
\hline \multicolumn{4}{|l|}{ CD15 } \\
\hline Mean \pm SD & $31.731 \pm 26.567$ & $4.972 \pm 3.808$ & $<0.001$ (HS) \\
\hline \multicolumn{4}{|l|}{ CD14 } \\
\hline Mean \pm SD & $38.421 \pm 39.79$ & $5.47 \pm 4.43$ & $<0.001 \mathrm{HS}$ \\
\hline \multicolumn{4}{|l|}{ CD 36} \\
\hline Mean \pm SD & $0.9800 \pm 1.004$ & $15.69 \pm 23.616$ & $0.027(\mathrm{~S})$ \\
\hline \multicolumn{4}{|l|}{$235 \mathrm{a}$} \\
\hline Mean \pm SD & $0.7143 \pm 0.3697$ & $17.798 \pm 16.831$ & $<0.001$ (HS) \\
\hline \multicolumn{4}{|l|}{ CD 61} \\
\hline Mean \pm SD & $2.881 \pm 1.749$ & $8.308 \pm 7.216$ & $0.01(\mathrm{~S})$ \\
\hline \multicolumn{4}{|l|}{ CD85K } \\
\hline Mean \pm SD & $43.235 \pm 19.465$ & $14.232 \pm 22.070$ & $<0.001$ (HS) \\
\hline
\end{tabular}

frequent association with MLIL but not specific marker for MLIL, because it also expressed on other cell lineage as lymphatic as mentioned by Xunlei (2016) [10]. CD85k is more frequent at age of below 35 years old without sex difference, and showed only significant value to TLC more than 50,000, and Hb level less than 7 $\mathrm{g} / \mathrm{dl}$, non-significant values with other hematological variables and organomegaly, this in relevant to the fact that its expression is indicative for biological origin of the MLIL and has prognostic value rather than tumor burden. These data are in agreeing with Kang et al. (2015) [16]. We noticed that; CD85k despite its positive frequency with MLIL, it is insignificantly correlate with other monocytic markers including CD36, CD14, CD15, but significant correlation with progenitor markers CD34, HLA-DR, may be originate to the biological role of each one 
differs in leukemia development, CD85k has a role in clonality association and immune escape, other results were correlated with clinical features, peripheral blood lymphocytosis, platelets count and hemoglobin level [21]. Also our results was consistent with Dobrowolska et al. (2013); who reported that there were no significant differences between CD85k positive or negative groups for the following parameters: age, sex, WBC, hemoglobin, and platelet count. In their work, they revealed that; the inhibitory receptor CD85k was sensitive and specific marker for MLIL diagnosis and follow up [22]. In this study there is no correlation between CD85K and P.Bl variables as WBCs less than 50,000 and $\mathrm{Hb}$ more than $7 \mathrm{~g} / \mathrm{dl}$ or platelet count in AML group and control group, while Cagnetta et al. (2014), in their study showed that the expression of CD $85 \mathrm{~K}$ was related to age, WBC counts, and Platelet counts in P.Bl respectively $(\mathrm{p}<0.05)$, CD85k was poorly associated with of hemoglobin level [23]. Our study found that there was positive significant correlation between $\mathrm{CD} 85 \mathrm{~K}$ and each of HLA-DR, negative significant correlation between CD85K and each of CD16, CD117, CD36, and no correlation with other types of IPT. When we made comparison between (M4, M5) and other types of AML, we found that there was significant statistical value of CD45, CD14, CD15, CD34, CD38, CD36, CD16, CD85K, HLADR, 235a. Dobrowolska et al. (2013), found in their research that CD85k was co-expressed by positive CD34/negative (CD117/CD14), M4/M5, also by more differentiated (negative CD34, CD117, CD14) leukemic cells. Overall, the co-expression with CD117 was presented 50\%, while co-expression with CD34 was seen in 39\% of MLIL [22]. According to Zhang (2015) and Petz et al. (2015); whom found that; the co-expression of CD85k and progenitor markers may be interpreted as asynchronous proliferation of leukemic cells [9] [24]. Thus, our findings are in accordance of Hao Cheng et al. (2011) and Cagnetta et al. (2014), whom reported that segregation of myeloid and monocytic precursors occurs at an early step of hematopoietic differentiation [1] [23]. Our results demonstrated that; the expression of ILT3 is absent in the control group, ILT3 is expressed in 19 patients in AML group (59.38\%), ILT3 was expressed by 14/14 cases of AML (M4/M5). This is in agreement with Dobrowolska et al. (2013) that show in their study that the inhibitory receptor ILT3 is a highly sensitive and specific marker for the diagnosis and monitoring of AML with monocytic differentiation, ILT3 was expressed by all cases of AML with monocytic differentiation and in none of the AML cases, which included M1/M2 and M3. The distinction between monocytic AML and other AML types is extremely important particularly in the differential diagnosis of AML with monocytic differentiation which requires different treatment strategies [22]. It is essential for the generation of regulatory $\mathrm{T}$ cells in humans; up regulation of this inhibitory receptor plays a crucial role in graft adaptation and protection against the recipient's immune response as reported by Xunlei et al. (2016) [10] [25].

\section{Conclusion}

These findings give the potential value of CD85k application in MLIL therapy. 
By the use of specific CD85k Mo Abs rendering leukemic cells more susceptible to anti-tumor $\mathrm{T}$ cell regulation. In practice it has no role in diagnosis or clinical assessment of the disease, but it's a main role in prediction after chemotherapy, so it is a good marker for follow up. In patients with ITP (control), CD85k has no biological role in pathophysiology of the disease. Here we find that in leukemia, CD85k expression is up regulated the reverse occurred in ITP, down regulation of CD85k, the usefulness of these data is that; some experimental manipulations in cellular signal transduction of ILT-3 in these diseases by downregulation in leukemia or upregulation in ITP can alter the fate of the disease. And be useful in therapy.

\section{Limitations of This Study}

The small sample size of the patients, most patients were died before complete the follow up.

\section{Conflicts of Interest}

The authors declare no conflicts of interest regarding the publication of this paper.

\section{References}

[1] Cheng, H., Mohammed, F., Nam, G., Chen, Y., Qi, J. and Garner, L.I. (2011) Crystal Structure of Leukocyte Ig-Like Receptor LILRB4 (ILT3/LIR-5/CD85k): A Myeloid Inhibitory Receptor Involved in Immune Tolerance. The Journal of Biological Chemistry, 286, 18013-18025. https://doi.org/10.1074/jbc.M111.221028

[2] Deng, M., Lu, Z., Zheng, J., Wan, X., Chen, X., Hirayasu, K., Sun, H., Lam, Y., Chen, L. and Wang, Q. (2014) A Motif in LILRB2 Critical for Angptl2 Binding and Activation. Blood, 124, 924-935. https://doi.org/10.1182/blood-2014-01-549162

[3] Podrez, E.A., Poliakov, E., Shen, Z., Zhang, R., Deng, Y., Sun, M., Finton, P.J., Shan, L., Gugiu, B., Fox, P.L., Hoff, H.F., Salomon, R.G. and Hazen, S.L. (2012) Identification of a Novel Family of Oxidized Phospholipids That Serve as Ligands for the Macrophage Scavenger Receptor CD36. Journal of Biological Chemistry, 277, Article ID: 3850316.

[4] Zhang, Z., Hatano, H., Shaw, J., Olde Nordkamp, M., Jiang, G., Li, D. and Kollnberger, S. (2015) The Leukocyte Immunoglobulin-Like Receptor Family Member LILRB5 Binds to HLA-Class I Heavy Chains. PLoS One, 10, Article ID: e0129063. https://doi.org/10.1371/journal.pone.0129063

[5] Meyers, J., Yu, Y., Kaye, J.A. and Davis, K.L. (2013) Medicare Fee-For-Service Enrollees with Primary Acute Myeloid Leukemia: An Analysis of Treatment Patterns, Survival, and Healthcare Resource Utilization and Costs. Applied Health Economics and Health Policy, 11, 275-286. https://doi.org/10.1007/s40258-013-0032-2

[6] Matutes, E., Morilla, R. and Morilla, A.M. (2012) Immunophenotyping Immunological Markers in Acute Leukemia. In: Dacie and Lewis Practical Hematology, 11th Edition, Churchill Livingstone Elsevier, London, 362-364.

[7] Jensen, M.A., Yanowitch, R.N., Reder, A.T., White, D.M, and Arnason, B.G. (2012) Immunoglobulin-Like Transcript 3, an Inhibitor of T Cell Activation, Is Reduced on Blood Monocytes during Multiple Sclerosis Relapses and Is Induced by Interfe- 
ron Beta-1b. Multiple Sclerosis, 16, 30-38.

https://doi.org/10.1177/1352458509352794

[8] Han, L., Qiu, P., Zeng, Z., Cortes, J. and Steven, M. (2015) Single-Cell Mass Cytometry Reveals Intracellular Survival/Proliferative Signaling in FLT3-ITD-Mutated AML Stem/Progenitor Cells. Cytometry Part A, 87, 346-356. https://doi.org/10.1002/cyto.a.22628

[9] Zhang, P., Yu, S., Li, H., Liu, C., Li, J., Lin, W., Gao, A., Wang, L., Gao, W. and Sun, Y. (2015) ILT4 Drives B7-H3 Expression via PI3K/AKT/m TOR Signaling and ILT4/B7-H3 Co-Expression Correlates with Poor Prognosis in Non-Small Cell Lung Cancer. Science China Life Sciences, 58, 1216 https://doi.org/10.1016/j.febslet.2015.06.037

[10] Kang, X., Kim, J., Deng, M., John, S., Chen, H., Wu, G., Phan, H. and Zhang, C. (2016) Inhibitory Leukocyte Immunoglobulin like Receptors Immune Checkpoint Protein and Tumor Sustaining Factors. Cell Cycle, 15, 25-40. https://doi.org/10.1080/15384101.2015.1121324

[11] Miller, K.B. and Pihan, G. (2013) Clinical Manifestations of Acute Myeloid Leukemia. In: Hoffman, R., Benz, E.J., Shattil, S.J., Furie, B., Cohen, H.J., Silberstein, L.E., McGlave, P. and Heslop, H.E., Eds., Hematology Basic Principles and Practice, 5th Edition, Chapter 11, Elsevier, Amsterdam, 933-950.

[12] Yonal, I., Hindilerden, F., Coskun, R., Dogan, O.L. and Nalcaci, M. (2011) A Leukemic Leukemia Cutis, the First Manifestation of Acute Myeloid Leukemia. Case Reports in Oncology, 4, 547-554. https://doi.org/10.1159/000334745

[13] Suciu-Foca, N., Vlad, G., Chang, C.-C., Liu, Z. and Colovai, A.L. (2013) Diagnosis and Treatment of Cancer Expressing ILT3 or ILT3 Ligand. Patentscope, $\mathrm{WO} / 2013 / 033734$.

[14] Greer, J.P., Baer, M.B. and Kinney, M.C. (2012) Acute Myeloid Leukemia in Adults. In: Greer, J.P., Foerster, J., Rodgers, G.M., Paraskevas, F., Glader, B., Arder, D.A. and Means, R.T., Eds., Wintrobe's Clinical Hematology, 12th Edition, Chapter 79, Lippincott Williams and Wilkins, Philadelphia, 1843-1888.

[15] Lu, H.K., Rentero, C., Raftery, M.J., Raftery, M.J., Borges, L., Bryant, K. and Tedla, N. (2011) Leukocyte Ig-Like Receptor B4 (LILRB4) Is A Potent Inhibitor of FcgammaRI-Mediated Monocyte Activation via Dephosphorylation of Multiple Kinases. The Journal of Biological Chemistry, 284, 34839-34848. https://doi.org/10.1074/jbc.M109.035683

[16] Kang, X., Lu, Z., Cui, C., Deng, M., Fan, Y., Dong, B., Han, X., Xie, F., Tyner, J.W. and Coligan, J.E. (2015) The ITIM Containing Receptors LAIR1 Is Essential for Acute Myeloid Leukemia Development. Nature Cell Biology, 17, 665-677. https://doi.org/10.1038/ncb3158

[17] Sharma, P. and Allison, J.P. (2015) Immune Checkpoint Targeting in Cancer Therapy: Toward Combination Strategies with Curative Potential. Cell, 161, 205-214. https://doi.org/10.1016/j.cell.2015.03.030

[18] Gupta, A., Pal, A. and Nelson, S.S. (2015) Immunophenotyping in Acute Leukemia: A Clinical Study. International Journal of Scientific Study, 3, 129-136.

[19] Arber, D.A., Orazi, A., Hasserjian, R., Thiele, J., Borowitz, M.J., Le Beau, M.M., Bloomfield, C.D., Cazzola, M. and Vardiman, J.W. (2016) The 2016 Revision to the World Health Organization Classification of Myeloid Neoplasms and Acute Leukemia. Blood, 127, 2391-2405.

[20] Deschler, B., Ihorst, G., Uwe, P., Platzbecker, U. and Lübbert, M. (2013) Parameters Detected by Geriatric and Quality of Life Assessment in 195 Older Patients with 
Myelodysplastic Syndromes and Acute Myeloid Leukemia Are Highly Predictive for Outcome. Haematologica, 98, 208-216.

https://doi.org/10.3324/haematol.2012.067892

[21] Ghosh, S., Shinde, S.C., Kumaran, G.S., Sapre, R.S., Dhond, S.R. and Badrinath, Y. (2003) Haematologic and Immunophenotypic Profile of Acute Myeloid Leukemia. An Experience of Tata Memorial Hospital. Indian Journal of Cancer, 40, 71-76.

[22] Dobrowolska, H., Gill, K.Z., Serban, G., Ivan, E., Lio, Q., Qiao, P., Suciu-Foca, N., Savage, D., Alobeid, B., Bhagat, G. and Colovia, A.I. (2013) Expression of Immune Inhibitory Receptor ILT3 in Acute Myeloid Leukemia with Monocytic Differentiation. Cytometry Part B: Clinical Cytometry, 84, 21-29.

[23] Cagnetta, A., Adamia, S., Acharya, C., Patrone, F., Miglino, M. and Nencioni, A. (2014) Role of Genotype-Based Approach in the Clinical Management of Adult Acute Myeloid Leukemia with Normal Cytogenetics. Leukemia Research, 38, 649-659. https://doi.org/10.1016/j.leukres.2014.03.006

[24] Betz, B.L. and Hess, J.L. (2015) Acute Myeloid Leukemia Diagnosis in the 21st Century. Archives of Pathology \& Laboratory Medicine, 134, 1427-1433.

[25] Boer, J.M., Veer, A.V., Rizopoulos, D., Fiocco, M., Sonneveld, E., Stanulla, M. and Conter, V. (2016) Prognostic Value of Rare IKZF1 Deletion in Childhood B-Cell Precursor Acute Lymphoblastic Leukemia: An International Collaborative Study. Leukemia, 30, 32-38. https://doi.org/10.1038/leu.2015.199 